\title{
Tasks of Attention Augment Rigidity in Mild Parkinson Disease
}

\author{
Dan A. Mendonça, Mandar S. Jog
}

\begin{abstract}
Objective: The purpose of this study was to determine whether tasks involving effortful attention would cause augmentation of rigidity in patients with mild Parkinson disease. Methods: In 17 subjects with mild Parkinson disease, rigidity in a single arm was assessed during various experimental conditions by a blinded movement disorders neurologist. Rigidity was scored separately at the wrist and the elbow using an ordinal scale. In three of the conditions, sustained attention was directed toward visual, auditory or movement-related stimuli. Two varieties of Froment maneuver served as positive controls: contralateral hand openingclosing or ipsilateral foot tapping. In addition, rigidity was assessed twice with subjects resting. The examiner was unaware of the sequence of experimental conditions and this was changed for each subject. Mean rigidity scores for the various experimental conditions were compared against the baseline state (an average of both trials with the patient resting) using a repeated measures ANOVA and posthoc Tukey-Kramer multiple comparisons test. Results: Rigidity was significantly increased from baseline with each of the attentional tasks ( $\mathrm{p}<0.01$ to $\mathrm{p}<0.001)$ and also with the two Froment maneuvers $(\mathrm{p}<0.001)$. Rigidity augmentation with contralateral hand opening-closing was significantly greater than with any of the attentional tasks ( $p<0.05$ to $p<0.001)$. Conclusion: Tasks of effortful attention did appear to augment rigidity in patients with mild Parkinson disease. We speculate that the greater augmentation seen with the Froment maneuver could have an anatomic basis.
\end{abstract}

RÉSUMÉ: Les tâches demandant de l'attention augmentent la rigidité dans la maladie de Parkinson légère. Objectif : Le but de cette étude était de déterminer si des tâches qui demandent une attention soutenue causent une augmentation de la rigidité chez les patients atteints d'une maladie de Parkinson légère (MPL). Méthodes : La rigidité dans un bras a été évaluée en aveugle par un neurologue spécialisé dans les troubles du mouvement chez 17 individus atteints de MPL dans différentes conditions expérimentales. La rigidité était évaluée séparément au niveau du poignet et du coude au moyen d'une échelle ordinale. Dans trois des expériences, l'attention était dirigée vers des stimuli visuels, auditifs ou en relation avec le mouvement. Deux types de manœuvres de Froment servaient de témoin positif : ouvrir et fermer la main contra-latérale et taper du pied homolatéral. De plus, la rigidité a été évaluée deux fois au repos. L'examinateur ne connaissait pas l'ordre des conditions expérimentales qui était modifié d'un sujet à l'autre. Les scores moyens de rigidité dans les différentes conditions expérimentales ont été comparés au score de base (la moyenne des deux essais effectués chez le sujet au repos) au moyen de l'ANOVA pour les mesures répétées et du test de comparaisons multiples a posteriori de Tukey-Kramer. Résultats : La rigidité était augmentée de façon significative par rapport aux conditions de base lorsque les sujets effectuaient des tâches demandant de l'attention ( $\mathrm{p}<0,01$ à $\mathrm{p}<0,001)$ et lors des deux manœuvres de Froment $(\mathrm{p}<0,001)$. Lorsque le sujet ouvrait et fermait la main opposée ( $<<0,05$ à $\mathrm{p}<0,001)$, la rigidité augmentait beaucoup plus que lors des tâches nécessitant de l'attention. Conclusion : Les tâches qui nécessitent une attention soutenue semblent augmenter la rigidité chez les patients atteints de MPL. Nous croyons que l'augmentation plus marquée observée lors de la manœuvre de Froment pourrait avoir un fondement anatomique.

Can. J. Neurol. Sci. 2008; 35: 501-505

The Froment maneuver is a method by which rigidity in one limb can be augmented during voluntary activity in a distant limb. ${ }^{1}$ Assessing rigidity with the help of an augmentation maneuver (also referred to as activation) is a formal part of the United Parkinson Disease Rating Scale (UPDRS). One version of the Froment maneuver involves examination of the tone in one arm whilst the patient clasps and unclasps the contralateral hand. Our personal observation has been that rigidity increases not only during this maneuver, but also just prior to it. More precisely, the enhanced rigidity is felt by the examining physician after the subject is instructed to move the contralateral hand and prior to voluntary movement occurring. We hypothesize that this increase in tone is related to an increased demand on the attentional mechanisms of the brain and/or

From the Grand River Hospital (DAM), Kitchener; Movement Disorders Program (DAM, MSJ), University of Western Ontario, London, Ontario, Canada. Received January 3, 2008. Final Revisions Submitted March 12, 2008. Reprint requests to: Mandar S. Jog, Department of Clinical Neurosciences, London Health Sciences Centre - University Campus, 339 Windermere Road, P.O. Box 5339, London, Ontario, N6A 5A5, Canada. 
involvement of secondary motor centers active just prior to movement.

In the late 1920's, Jules Froment described a possible link between attention and rigidity in IPD. He observed that when a patient's eyes and head were turned toward the arm being examined, or when a patient was asked to concentrate his or her attention on the examined arm, rigidity in the arm was augmented. ${ }^{2}$ More generally, Froment conceptualized parkinsonian rigidity as a consequence of disordered mechanisms for standing stabilization. For instance, he described how rigidity could be increased by changing the static posture of the body or during a task requiring maintenance of standing balance. ${ }^{1}$

The aim of the present study was to determine whether experimental conditions that require sustained attention would modify upper extremity rigidity in subjects with mild IPD.

\section{METHODS}

\section{Ethics}

The study protocol was approved by our institution's ethics review board and each patient provided written informed consent prior to participating.

\section{Study population}

Patients with IPD (United Kingdom Parkinson Brain Bank criteria) seen at the outpatient movement disorders clinic at the London Health Sciences Centre with mild rigidity in one or both arms (UPDRS rigidity score of 1 or 2 in one arm and combined UDPRS rigidity score in both arms of 1 to 4) were eligible to enroll. Exclusion criteria included: evidence of dementia on history, screening mini-mental status exam (MMSE) $<28$, and any factors that would prevent subjects from reading English letters on a computer screen or listening to computer-issued sounds over earphones. As this was a preliminary study, no sample size calculation was performed.

\section{Format for rigidity assessments}

Each patient took part in a single 45 minute session. The unblinded examiner (Examiner B) performed a focused examination including Hoehn and Yahr staging and assessment of rigidity in the upper extremities. For each subject, only one arm was studied in the subsequent experiment. The arm to be studied was chosen based on the presence of rigidity augmentation with the Froment maneuver. If augmentation occurred in both arms, then the arm with less baseline rigidity was used.

Patients were seated squarely in front of a computer screen in a comfortable chair with their arms supported on the arms of the chair. Examiner A (MJ), a movement disorders neurologist with more than twelve years experience, performed all assessments of rigidity for the experiment and these assessments were blinded. In the case of patients requiring treatment, assessments were performed with patients in their $\mathrm{ON}$ state. Examiner A was seated beside the subject in close proximity to the arm to be examined. He wore a blindfold and earplugs and was cued in a loud voice to start or stop examining the arm by Examiner B (DM). The arm was examined under seven conditions with one minute rest between each of these examinations. Examiner A manipulated the wrist and the elbow according to a pre- formulated sequence that was repeated for each patient. Rigidity at both joints was graded on an ordinal scale ranging from 0 to 4 . The rigidity score was assigned based on the maximal rigidity detected $(0=$ none, $1=$ mild, $2=$ moderate, $3=$ severe, $4=$ almost immovable). If the maximal rigidity occurred only inconsistently then the score was downgraded to 0.5 below the maximal rigidity detected. The sequence of experimental conditions was changed for each patient and Examiner A was unaware of this sequence.

Examiner B was unblinded and performed the following functions: timed the segments of the experiment, instructed Examiner A to start or stop examination of the subject's arm, recorded rigidity scores called out by Examiner A, cued subjects to start or stop maneuvers and monitored performance of attentional tasks. No talking was allowed during the experiment other than Examiner B instructing Examiner A to start or stop his assessment and Examiner A calling out rigidity scores.

\section{Experimental conditions}

Three of the experimental conditions were tasks requiring sustained attention. In the visual attention task, subjects were asked to view the computer screen where letters $(4.5 \mathrm{~cm} \mathrm{x} 4.0$ $\mathrm{cm}$ ) were flashed at a rate of $1 \mathrm{~Hz}$ in the centre of the screen. Patients were instructed to allow their lips to part loosely $(\sim 1$ $\mathrm{cm})$ and then close their lips briefly each time they saw the letter "X". The target letter appeared five times in 30 seconds. In the auditory attention task, subjects were asked to listen to earphones attached to the computer. Twenty-five letters were read out by the computer over 30 seconds. Patients were again instructed to allow their lips to part loosely $(\sim 1 \mathrm{~cm})$ and then close their mouth briefly each time they heard the letter "O". The target letter was read four times in 30 seconds. In the attention to movement task, subjects were asked to concentrate on the unexamined hand that was situated palm-side down on the desk in front of them. Examiner B passed his finger sequentially over top of the distal interphalangeal joint of individual fingers in standard order (thumb, index, middle, etc., and then back). There was a brief pause over each finger of $\sim 1$ second. If Examiner B touched the finger, patients were instructed to lift the finger momentarily off the table $(\sim 0.5 \mathrm{~cm})$. Individual fingers were randomly touched on four occasions over 30 seconds. Subjects rehearsed all three tasks prior to the experiment until they were able to perform them without any errors (no omissions and no false starts). Patients normally required one or two practice trials.

On two occasions, assessment of arm rigidity was performed with the subject resting. Two positive controls were also included: hand opening-closing contralateral to the arm being examined and foot tapping ipsilateral. Again, the sequence of all conditions (controls or attentional tasks) was switched around for each patient and Examiner A was blind to this.

Fifteen seconds before each trial, Examiner B would point to a piece of paper to communicate to the patient the next task to be performed. During the tasks of attention, if the subject did not respond to all test stimuli requiring a response then it was assumed that the subject was not attending sufficiently and the trial was repeated. In this case, only the repeated trial was included in the analysis. 


\section{Statistical analysis}

Each of Examiner A's assessments were transformed into a combined rigidity score by adding the rigidity scores for the wrist and elbow. Baseline rigidity for each patient was defined as the mean combined rigidity score derived from the two trials with the patient in a relaxed state. The mean combined rigidity scores for the five experimental conditions $(n=17)$ were compared against the baseline rigidity $(n=17)$. Raw data was assessed for normality using the Kolmogorov-Smirnov test. Because the same patients were tested under multiple conditions (paired data), means were compared using a repeated measures ANOVA with a post-hoc Tukey-Kramer multiple comparisons test.

In order to assess Examiner A's consistency in grading rigidity (intra-rater reliability), the two combined rigidity scores obtained with patients resting were used to calculate the intraclass correlation coefficient.

\section{RESULTS}

Seventeen patients (11 men and 6 women) with mild Parkinson disease (Hoehn and Yahr stage II or III) were enrolled in the study. Table 1 summarizes the baseline characteristics of subjects.

Table 2 summarizes the combined rigidity score data for subjects. Raw data passed the Kolmogorov-Smirnov test for normality. There was a statistically significant increase in mean combined rigidity for each of the attentional tasks when compared to baseline rigidity (movement-related task $\mathrm{p}<0.001$; visual task $\mathrm{p}<0.001$; auditory task $\mathrm{p}<0.01$ ). There was also a statistically significant increase in mean combined rigidity for both types of Froment maneuver when compared to baseline rigidity ( $\mathrm{p}<0.001)$. There was no statistical difference in mean combined rigidity between the two types of Froment maneuver or amongst the three experimental tasks involving sustained attention ( $p>0.05)$. There was a statistically significant difference in augmentation with contralateral hand openingclosing (greater activation) than with any of the three conditions involving sustained attention (movement-related task $\mathrm{p}<0.05$; visual task $\mathrm{p}<0.01$; auditory task $\mathrm{p}<0.001$ ).

The intraclass correlation coefficient, calculated using the two combined rigidity scores for each patient in the resting state, was 0.85 . This indicates very good consistency in Examiner A's blinded ratings of rigidity at least when patients were relaxed.

\section{Discussion}

Rigidity is one of the cardinal signs of IPD and is detected by the examiner as increased resistance to passive mobilization of a joint. Unlike spasticity, it is independent of both velocity of limb displacement and whether extensor or flexor muscles are stretched. Another distinguishing feature is that deep tendon reflexes are usually normal. The pathophysiology of baseline rigidity in IPD is still open to debate. Delwaide et $\mathrm{al}^{3-4}$ make a compelling argument that baseline rigidity in IPD is caused by decreased activity in the reticulospinal tract. We have wondered whether this might also explain the flexed (or so-called simian) posture seen in patients with IPD. Importantly, the anatomic pathway(s) underlying augmentation of rigidity could be different from that/those underlying baseline rigidity. The final effectors in this sequence are the motor neurons subserving cocontracting agonist and antagonist muscles in the limbs.

Not surprisingly, our results confirm that contralateral hand opening-closing and ipsilateral foot tapping ${ }^{5}$ are both effective in augmenting rigidity in the upper extremity. The effectiveness of ipsilateral foot tapping is instructive as it opposes the notion that rigidity augmentation occurs only between homologous parts on different sides of the body (one moved voluntarily by the subject and the other passively by the examiner) on different sides of the body. It is unlikely therefore that augmentation is due to

Table 1: Patient characteristics

\begin{tabular}{l|c}
\hline mean age (range) & 67.4 years $(48-80)$ \\
\hline patient sex & 11 men; 6 women \\
\hline mean MMSE score (range) & $29.1(28-30)$ \\
\hline arm examined & 10 right; 7 left \\
\hline disease duration (range) & 1 week to 14 years \\
\hline Hoehn and Yahr stage (range) & II to III \\
\hline subjects on dopaminergic drugs & 11 of 17 \\
& $\begin{array}{c}\text { 9 on levodopa/carbidopa } \\
\text { (mean levodopa daily dose: } 492.2 \mathrm{mg}) \\
\text { 3 on dopamine agonists }\end{array}$ \\
\hline
\end{tabular}

MMSE $=$ mini-mental status exam 
Table 2: Clinical rigidity ratings

Combined Rigidity Scores (elbow and wrist added)

$\mathrm{n}=17$

\begin{tabular}{|c|c|c|c|c|c|c|}
\hline & \multirow{2}{*}{$\begin{array}{l}\text { Baseline } \\
\text { rigidity }\end{array}$} & \multicolumn{2}{|c|}{ Augmentation Maneuver } & \multicolumn{3}{|c|}{ Attentional Tasks } \\
\hline & & $\begin{array}{c}\text { contralateral } \\
\text { hand }\end{array}$ & $\begin{array}{l}\text { ipsilateral } \\
\text { foot }\end{array}$ & auditory & visual & movement \\
\hline $\begin{array}{l}\text { mean rigidity } \\
\text { score }( \pm \mathrm{SD})\end{array}$ & $\begin{array}{c}1.82 \\
( \pm 1.33)\end{array}$ & $\begin{array}{c}4.47 * \\
( \pm 1.36)\end{array}$ & $\begin{array}{c}3.94 * \\
( \pm 1.51)\end{array}$ & $\begin{array}{c}3.03 \dagger \\
( \pm 1.63)\end{array}$ & $\begin{array}{c}3.21 * \\
( \pm 1.42)\end{array}$ & $\begin{array}{c}3.53 * \\
( \pm 1.43)\end{array}$ \\
\hline $\begin{array}{c}\text { mean } \\
\text { difference } \\
(95 \% \mathrm{CI})\end{array}$ & & $\begin{array}{c}2.65 \\
(1.85-3.44)\end{array}$ & $\begin{array}{c}2.12 \\
(1.32-2.91)\end{array}$ & $\begin{array}{c}1.21 \\
(0.41-2.00)\end{array}$ & $\begin{array}{c}1.38 \\
(0.59-2.18)\end{array}$ & $\begin{array}{c}1.71 \\
(0.91-2.50)\end{array}$ \\
\hline
\end{tabular}

* significant change from baseline rigidity $\mathrm{p}<0.001$ (Tukey-Kramer multiple comparisons test); $\uparrow$ significant change from baseline rigidity $\mathrm{p}<0.01$

(Tukey-Kramer multiple comparisons test)

segmental decussation of neural pathways within the spinal cord. The effectiveness of both types of Froment maneuver make it more likely that augmentation occurs due to modification of descending supraspinal input onto motor neurons at multiple levels and bilaterally.

In three of the experimental conditions in the present study, patients were asked to react to a target stimulus (auditory, visual or movement-related) within a string of non-target stimuli. These tasks required sustained, effortful attention. Even during presentation of non-target stimuli, an active suppression of movement was required to prevent false responses. Because patients had to be ready to respond to target stimuli, there was anticipation of movement or a preparedness to move. For this reason, it is possible that centers involved in motor planning were also engaged. From a behavioral standpoint, there may have been a reward component inherent in the tasks of attention. Patients were aware that Examiner B was monitoring their responses for correctness and that mistakes in performance would result in repetition of the trial.

During all three conditions designed to engage the brain's attentional system (and perhaps its motor planning centers), there was a significant augmentation of rigidity. Although it is difficult to propose an anatomical basis for this effect based on our data alone, data from other experiments provides additional clues. Tasks of attention likely activate basal ganglia structures. One reason to believe attentional tasks involve basal ganglia structures is that tests of attention and decision making are negatively affected in conditions where there is basal ganglia pathology, such as IPD. ${ }^{6,7}$ In addition, electrode recording in primates and the results of neuro-computational modeling implicate the basal ganglia in motor plan selection where there is a reward component. ${ }^{8}$ By engaging the basal ganglia, attentional tasks may have altered outflow from these structures to upstream or downstream neural centers (for instance, the reticulospinal tract) and caused the observed augmentation of rigidity.
Both types of Froment maneuver (hand opening-closing and foot tapping) caused a more pronounced augmentation of baseline rigidity than all three attentional tasks employed. Once again, it is difficult to speculate on the underlying anatomy based on our data. Our feeling is that the basal ganglia were engaged to a much smaller extent during these maneuvers. These movements were simple, repetitive and did not require effortful attention. While the corticospinal tract is not thought to play a role in generation of baseline rigidity in IPD, ${ }^{3-4}$ it might be involved in rigidity augmentation during repetitive, voluntary movements. Studies employing transcranial magnetic stimulation (TMS) indicate that there may be decreased intracortical inhibition of motor cortex in IPD. ${ }^{9}$ An informative example of "spillover" from motor cortex during voluntary movement in patients with IPD is the mirror movements observed clinically ${ }^{10}$ and detected with EMG.${ }^{11}$ The TMS studies implicate transcallosal spread from one area of motor cortex to another in mirror movements production. ${ }^{12}$

If it is true that tasks of attention increase limb rigidity, there are potential links to the findings of previous studies. For instance, it has been observed that various gait parameters worsen in IPD when attention is engaged by means of a concurrent task unrelated to walking, such as digit subtraction. ${ }^{13}$ It is conceivable that worsened rigidity with the attentional task could contribute to gait impairment. Conversely, external sensory cues have been shown to improve gait initiation ${ }^{14}$ and other gait parameters ${ }^{15}$ in patients with IPD. Improvement might occur in this context because the sensory cues employed are not competing for attentional resources. Instead, they are congruent or in sync with the main task (of walking). There is evidence, in fact, to suggest that these cues are more properly viewed as enhanced sensory feedback as opposed to attentional cues. ${ }^{16-17}$

There were several potential limitations of the study. Rigidity assessment was performed clinically and by a single examiner (MJ). While the consistency of clinical rigidity scoring is 
imperfect, the intra-rater reliability for ratings with patients in the relaxed state was high in this study. Unfortunately, mechanical devices for rigidity measurement are expensive, not easily obtained and used in only a handful of laboratories. To limit the possibility of bias affecting Examiner A's scoring, two negative controls were included and the sequence of experimental tasks was changed for each patient. It has also been pointed out that the small-amplitude mouth or finger movements performed by the subject during the tasks of attention, although performed singly (many seconds apart), may have acted like a more typical Froment maneuver. This difficulty is hard to overcome because tasks of attention require some type of immediate response by the subject (to indicate successful registration of a positive stimulus). A delayed response by the subject (after the attentional task) would bring in the role of memory.

Our results support the hypothesis that experimental tasks that engage the brain's attentional system can increase the rigidity of mild IPD. Rigidity augmentation with attentional tasks was not as great as that seen with contralateral hand opening-closing. We speculate that the greater augmentation with the more conventional Froment maneuver, as opposed to attentional tasks, may have an anatomic basis. These findings are another clue in the ongoing effort to explain the generation of motor symptoms in IPD.

\section{ACKNOWLEDGEMENTS}

The authors thank Adrian Kwasek for his help in computer programming, Valérie Prat for her help in translating the work of Dr. Jules Froment and Dr. Jeremy Moeller for his help in proofreading.

\section{REFERENCES}

1. Broussolle E, Krack P, Thobois S, Xie-Brustolin J, Pollak P, Goetz CG. Contribution of Jules Froment to the study of parkinsonian rigidity. Mov Disord. 2007;22:909-14.

2. Froment J, Dubouloz P. Rigidité parkinsonienne et rigidité de déséquilibre varient au bras dès que l'attention prend une direction nouvelle. Rev Neurol. (Paris) 1929;I: 255-7.
3. Delwaide PJ. Parkinsonian rigidity. Funct Neurol. 2001;16:147-56.

4. Delwaide PJ, Pepin JL, De Pasqua V, de Noordhout AM. Projections from basal ganglia to tegmentum: a subcortical route for explaining the pathophysiology of Parkinson's disease signs? J Neurol. 2000;247:II/75-II/81.

5. Hong M, Perlmutter JS, Earhart GM. Enhancement of rigidity in Parkinson's disease with activation. Mov Disord. 2007;22: 1164-8.

6. McAuley, JH. The physiological basis of clinical deficits in Parkinson's disease. Prog Neurobiol. 2003;69:27-48.

7. Brown RG, Marsden CD. Internal versus external cues and the control of attention in Parkinson's disease. Brain. 1988;111: 323-45.

8. Daw ND, Doya K. The computational neurobiology of learning and reward. Curr Opinion Neurobiol. 2006;16:199-204.

9. Ridding MC, Inzelberg R, Rothwell JC. Changes in excitability of motor cortical circuitry in patients with Parkinson's disease. Ann Neurol. 1995;37:181-8.

10. Vidal JS, Derkinderen P, Vidailhet M, Thobois S, Broussolle E. Mirror movements of the non-affected hand in hemiparkinsonian patients: a reflection of ipsilateral motor overactivity? J Neurol Neurosurg Psychiatry. 2003;74:1352-3.

11. Cincotta M, Giovannelli F, Borgheresi A, Balestrieri F, Vanni P, Ragazzoni A, et al. Surface electromyography shows increased mirroring in Parkinson's disease patients without overt mirror movements. Mov Disord. 2006;21:1461-5.

12. Li JY, Espay AJ, Gunraj CA, Pal PK, Cunic DI, Lang AE, et al. Interhemispheric and ipsilateral connections in Parkinson's disease: relation to mirror movements. Mov Disord. 22;813-21.

13. O'Shea S, Morris ME, Iansek R. Dual task interference during gait in people with Parkinson disease: effects of motor versus cognitive secondary tasks. Phys Ther. 2002;82:888-97.

14. Jiang Y, Norman KE. Effects of visual and auditory cues on gait initiation in people with Parkinson's disease. Clin Rehabil. 2006; 20:36-45.

15. Thaut MH, McIntosh GC, Rice RR, Miller RA, Rathbun J, Brault JM. Rhythmic auditory stimulation in gait training for Parkinson's disease patients. Mov Disord. 1996;11:193-200.

16. Azulay JP, Mesure S, Amblard B, Blin O, Sangla I, Pouget J. Visual control of locomotion in Parkinson's disease. Brain. 1999;122: $111-20$.

17. Azulay JP, Mesure S, Blin O. Influence of visual cues on gait in Parkinson's disease: contribution to attention or sensory dependence? J Neurol Sci. 2006;248:192-5. 